\title{
A FISCALIZAÇÃO DAS MEDIDAS PROTETIVAS DE URGÊNCIA PARA EFETIVIDADE DA LEI MARIA DA PENHA
}

\section{THE SURVEILLANCE OF PROTECTIVE EMERGENCY MEASURES FOR EFFECTIVENESS OF THE MARIA DA PENHA LAW}

\author{
lan Lisboa \\ Bacharel em Direito \\ e-mail: ianlisboa@hotmail.com \\ Márcio Júnio Batista Pereira \\ Especialista em Direito do Trabalho, Fundação Pres. Antônio Carlos \\ e-mail: marciojuniotoadv@hotmail.com \\ Fernanda da Silva Freitas \\ Especialista em Docência do Ensino Superior, Fundação Pres. Antônio Carlos \\ e-mail: ferna-freitas@hotmail.com
}

\section{Resumo}

Após treze anos de promulgação da lei 11.340/2006, a famosa Lei Maria da Penha ainda possui obstáculos para alcançar sua efetividade. Ocorre que, alguns Estados têm utilizado de mecanismos alternativos para prevenir à violência doméstica e fiscalizar o cumprimento das medidas protetivas de urgência. Os referidos mecanismos são o foco do presente artigo, o qual aborda o surgimento da Lei Maria da Penha, a importância das medidas protetivas de urgência e os mecanismos alternativos promovidos pelos Estados para sua fiscalização. O estudo é relevante, tendo em vista, a necessidade de se encontrar soluções para proteção da vítima de violência doméstica. Trata-se de um estudo dedutivo e bibliográfico. O estudo realizado permitiu concluir que as ações alternativas são eficazes, todavia, devem ser expandidas em todo território nacional para coibir a prática da violência doméstica.

Palavras-chave: Violência; Medidas; Efetividade; Fiscalização.

\begin{abstract}
After thirteen years of enactment of Law 11.340 / 2006, the famous Maria da Penha Law still has obstacles to its effectiveness. However some states have used alternative measures to prevent domestic violence and to enforce urgent protective measures. These measures are the focus of this article, which deals with the emergence of the Maria da Penha Law, the importance of urgent protective measures and the alternative measures promoted by the federal states for its enforcement. The study is relevant, considering the need to find solutions to protect the
\end{abstract}


victim of domestic violence. It is a deductive and bibliographical study. The study concluded that alternative actions are effective, but should be expanded throughout the national territory to curb the practice of domestic violence.

Keywords: Violence; Measures; Effectiveness; Supervision.

\section{INTRODUÇÃ̃O}

A violência doméstica, lamentavelmente, reflete a realidade assombrosa de muitas mulheres, podendo ser considerada como uma violência "democrática", afinal, atinge mulheres de todas as classes sociais, idades, raça e lugares do Brasil. Trata-se de um assunto de segurança pública, pois não afeta somente a mulher vítima, mas todos que a rodeiam, em especial seus familiares.

A Lei Maria da Penha, lei n 11.340 de 07 de agosto de 2006, é voltada exclusivamente à proteção da vítima de violência doméstica, é um marco para o ordenamento jurídico brasileiro. Noutro tempo não havia a quem recorrer, era comum a noção de violência doméstica como um problema de âmbito privado que deveria ser resolvido sem intervenção de terceiros. Ao contrário, nos dias atuais há uma considerável disposição da sociedade e do Poder Público em combater as agressões. O homem agressor já não é visto apenas como um "covarde".

Posto isso, o estudo pretende ressaltar que apesar da legislação ser uma grande conquista, o número de mulheres vítimas de violência doméstica no Brasil ainda é preocupante. Porém, alguns Estados do país têm utilizado de mecanismos alternativos para aumentar a eficácia da Lei Maria da Penha e da fiscalização das Medidas Protetivas de Urgência. Diante desse contexto, indaga-se se esses mecanismos são eficazes para fiscalização das medidas protetivas de urgência. Os referidos mecanismos são o foco do presente estudo e serão apresentados realizando uma explicação de como se desenvolvem e sua importância na luta contra a violência doméstica.

\section{A LEI MARIA DA PENHA E A VIOLÊNCIA DOMÉSTICA}

A violência refere-se ao uso da força física, intelectual ou psicológica, a fim de subjulgar outrem a sofrimento, intimidação ou dano. A violência doméstica e familiar exercida pelo homem contra a mulher é uma violência fundada no gênero, pois possui como fundamento a tradição do patriarcalismo, a qual engloba o histórico e discriminatório pensamento da mulher 
em posição hierárquica inferior a do homem na sociedade. Em 2002, o Ministério da Saúde conceituou violência doméstica como: "toda ação ou omissão que prejudique o bem-estar, a integridade física, psicológica ou a liberdade e o direito ao pleno desenvolvimento de outro membro da família." (BRASIL, 2002).

Ocorre que por muito tempo a violência doméstica não foi considerada como um problema político. A inexistência de uma política que fosse capaz de coordenar e integrar os esforços dos poderes governamentais dificultava a execução de ações mais efetivas de combate à violência doméstica, ao mesmo tempo em que não potencializava as iniciativas existentes.

Em 07 de agosto de 2006, a vinda da Lei Maria da Penha (LMP) rompeu, uma longa tradição jurídica de não reconhecimento da violência contra as mulheres. A LMP trata a violência doméstica como um problema de responsabilidade estatal e em 2019, completou 13 anos de vigência, porém, ainda há lacunas que devem ser objeto de discussão pelo Poder Público para seu aperfeiçoamento.

A Lei Maria da Penha recebeu essa nomenclatura em respeito à luta da farmacêutica cearense Maria da Penha Maia Fernandes, que fez sua causa repercutir nacional e internacionalmente. Vítima de violência doméstica e símbolo da luta pelos direitos de proteção às mulheres no Brasil, em 1983 recebeu do seu marido, Marco Antônio Heredia Viveiros, um tiro de espingarda enquanto dormia. Em viturde da tentativa de homicídio ficou paraplégica e se viu presa em uma cadeira de rodas. Em livro de sua autoria, Maria da Penha relata:

\begin{abstract}
Acordei de repente com um forte estampido dentro do quarto. Abri os olhos. Não vi ninguém. Tentei mexer-me, mas não consegui. Imediatamente fechei os olhos e um só pensamento me ocorreu: "Meu Deus, o Marco me matou com um tiro". Um gosto estranho de metal se fez sentir, forte, na minha boca, enquanto um borbulhamento nas minhas costas me deixou ainda mais assustada. Isso me fez permanecer com os olhos fechados, fingindo- me de morta, pois temia que Marco me desse um segundo tiro. (FERNANDES, 2012, p. 36).
\end{abstract}

Após longo período no hospital, a farmacêutica retornou para casa onde continuou sendo vítima de agressões e sofreu a segunda tentativa de homicídio, mas dessa vez por eletrocussão enquanto tomava banho. Maria da Penha relata: "E, enquanto me desesperava, tentando afastarme daquele local, Marco retrucava para que eu deixasse de besteira, pois aquele choquezinho de nada não dava para matar ninguém.” (FERNANDES, 2012, p. 88).

Mesmo com limitações físicas, Maria da Penha inaugurou uma batalha no Judiciário pela condenação do seu agressor, mas devido à morosidade e omissão da Justiça brasileira perante o caso, somente com a ajuda de $\mathrm{ONG}^{\prime}$ s, conseguiu remeter o caso à Comissão 
Interamericana de direitos humanos (OEA), que condenou o Brasil por negligência e omissão em relação à violência doméstica.

A Lei Maria da Penha é fruto das recomendações da OEA, para que o Brasil criasse uma legislação própria para proteção das vítimas de violência doméstica. Ao assina-lá, o Presidente da República, na época Luiz Inácio Lula da Silva, disse: "Esta mulher renasceu das cinzas para se transformar em um símbolo da luta contra a violência doméstica no nosso país" (FERNANDES, 2012, p. 14).

A positivação dessa lei especialmente voltada à proteção da mulher vítima de violência doméstica é um marco positivo para história brasileira, pois a agressão em âmbito familiar permeia nossa cultura desde a colonização. Segundo Dias ( 2007, p. 15).:

\begin{abstract}
Ditados populares, repetidos de forma jacosa, absolveram a violência doméstica: “em briga de marido e mulher ninguém mete a colher"; "ele pode não saber por que bate, mas ela sabe por que apanha". Esses, entre outros ditos repetidos como brincadeira, sempre esconderam uma certa conivência da sociedade para com a violência doméstica. Talvez o mais terrível deles seja: "mulher gosta de apanhar", engano gerado pela dificuldade que elas têm de denunciar o seu agressor. Seja por medo, por vergonha, por não ter para onde ir, por receio que não conseguir se manter sozinha e sustentar os filhos, o fato é que a mulher resiste em buscar a punição de quem ama ou, ao menos, um dia amou.
\end{abstract}

Após a lei entrar em vigor, as mulheres têm recebido apoio e informação para denunciarem os agressores. Além disso, o Poder Legislativo tem ampliado as normas de proteção à mulher. Antes o Brasil nem contabilizava as mortes de mulheres pela condição de gênero, conduta que só veio a ser qualificada em 2015, com a lei n. 13.104, Lei do Feminicídio, que alterou nosso Código Penal.

Em todo o Brasil o principal canal de orientação sobre direitos e serviços públicos para a população feminina é o Ligue 180, criado em 2005 pela Secretaria de Políticas para as Mulheres da Presidência da República (SPM-PR). Em 2018, o Ligue 180, oferecido pelo Ministerio da Mulher, da Família e dos Direitos Humanos (MMFDH), recebeu 92.663 denúncias de violência contra mulher.

No primeiro semestre de 2019, o canal recebeu 46.510 denúncias, dentre estas foram: ameaças (1.844), cárcere privado (1.243), feminicídio (36), tentativa de feminicídio (2.688), homicídio (6), tentativa de homicídio (67), trabalho escravo (14), tráfico de mulheres (16), violência contra a diversidade religiosa (11), violência doméstica e familiar (35.769), violência 
física (1.105), moral (1.921), obstétrica (116), policial (385), sexual (1.109) e virtual (180) ${ }^{1}$. Segundo o Sistema de Ouvidoria Nacional de Direitos Humanos (SONDHA) representa um aumento de $10,93 \%$ em relação ao mesmo periodo do ano anterior.

No entanto, apesar dos dados do Ligue 180, muitas mulheres ainda sofrem caladas em razão, principalmente, do medo de sofrerem mais violência do agressor e/ou de não conseguirem sustentar a si e/ou a seus filhos ou de serem socialmente excluídas. A vítima pode prosseguir por anos em uma relação que lhe traga dor e sofrimento sem nunca prestar denúncia das agressões sofridas, ou mesmo, quando fazê-la, em alguns casos ser convencida ou até mesmo forçada a desistir de levar seu desejo adiante.

\section{CICLO DA VIOLÊNCIA}

O artigo $5^{\circ}$ da Lei Maria da Penha define violência doméstica e familiar como qualquer ação ou omissão baseada no gênero que lhe cause morte, lesão, sofrimento físico, sexual ou psicológico e dano moral ou patrimonial. Para compreender a particularidade da violência doméstica contra a mulher, é primordial pensar em um verdadeiro "ciclo da violência", que abarca as várias modalidades de agressões.

Ciclo da violência foi um termo criado em 1979, por uma psicóloga norte-americana, Lenore Walker, que identificou um processo contínuo e repetitivo em que a vítima está inserida. Segundo a psicóloga o ciclo é composto de três fases: da tensão, da explosão e da "lua de mel"2.

$\mathrm{Na}$ maioria dos casos, o agressor é o companheiro da vítima. Ele inicia uma violência psicológica gerando uma progressiva perda de autoestima e confiança da vítima, até que ela acredite ser merecedora e responsável pelas agressões, se tornando extremamente submissa aos desejos do agressor e aceitando a agressão como um castigo merecido. Sobre o assunto Dias explica:

O ciclo da violência é perverso. Primeiro vem o silêncio seguido da indiferença. Depois surgem as reclamações, reprimendas, reprovações e começam os castigos e as punições. Os gritos transformam-se em empurrões, tapas, socos, pontapés, num crescer sem fim. As agressões não se cingem à pessoa da família, o varão destrói seus objetos de estimação, a humilha diante dos filhos. Sabe que estes são os seus pontos fracos e os usa como massa de manobra, ameaçando maltratá-los. (2007, p. 18)

\footnotetext{
${ }^{1}$ BRASIL. Ministério da Mulher, da Família e dos Direitos Humanos. Balanço anual: Ligue 180 recebe mais de 92 mil denúncias de violações contra mulheres. 06 de agosto de 2019 . Disponível em: <https://www.mdh.gov.br/todas-as-noticias/2019/agosto/balanco-anual-ligue-180-recebe-mais-de-92-mildenuncias-de-violacoes-contra-mulheres>. Acesso em: 19 de agosto de 2019.

${ }^{2}$ FERNANDES, Tainah. O que é como enfrentar e como sair do ciclo da violência. Agencia Patrícia Galvão. Disponível em: <https://agenciapatriciagalvao.org.br/destaques/o-que-e-como-enfrentar-e-como-sair-do-ciclo-daviolencia>. Acesso em: 10 de agosto de 2019.
} 
Na primeira fase, o agressor mostra-se irritado, culpa a vítima por coisas simples e irrelevantes. Geralmente nessa fase ocorre violência verbal, psicológica e moral. A vítima tende a negar e esconder a situação. Nas palavras de Soares (2005, p. 23):

Nessa fase podem ocorrer incidentes menores, como agressões verbais, crises de ciúmes, ameaças, destruição de objetos etc. Nesse período de duração indefinida, a mulher geralmente tenta acalmar seu agressor, mostrando-se dócil, prestativa, capaz de antecipar cada um de seus caprichos ou buscando sair do seu caminho. Ela acredita que pode fazer algo para impedir que a raiva dele se torne cada vez maior. Sente-se responsável pelos atos do marido ou companeiro e pensa que se fizer as coisas corretamente os incidentes podem terminar. Se ele explode, ela assume a culpa. Ela nega sua própria raiva e tenta se convencer de que "talvez ele esteja mesmo cansado ou bebendo demais".

Em seguida vem à fase da explosão, o ponto máximo da violência. Essa é a fase mais curta, sendo muito comum o uso de arma branca ou de fogo para intimidar a vítima. Ao descrever a segunda fase, Soares diz que:

A segunda fase é marcada por agressões agudas, quando a tensão atinge seu ponto máximo e acontecem os ataques mais graves. A relação se torna não administrável e tudo se transforma em descontrole e destruição. Algumas vezes a mulher percebe a aproximação da segunda fase e acaba provocando os incidentes violentos, por não suportar mais o medo, a raiva e a ansiedade. A experiência já lhe ensinou, por outro lado, que essa é a fase mais curta e que será seguida pela fase 3 , da lua de mel. (SOARES, 2005, p. 23).

Na terceira fase ocorre o arrependimento do agressor. É a fase do ciclo em que a vítima está mais vulnerável e acredita no pedido de desculpas do agressor. Este, por sua vez, rodeia a vítima de forma carinhosa levando-a a acreditar que de fato houve uma mudança em seu comportamento. Nessa perspectiva, Dias afirma que:

Depois de um episódio de violência, vem o arrependimento, pedidos de perdão, choro, flores promessas etc. Cenas de ciúmes são recebidas como prova de amor, e a vítima lisonjeada. O clima familiar melhora e o casal vive uma nova lua de mel. Ela sente-se protegida, amada, querida e acredita que ele vai mudar. Tudo fica bom até a próxima cobrança, ameaça, grito tapa. (...) A ferida sara, os ossos quebrados recuperam, o sangue seca, mas a perda da autoestima, o sentimento de menos valia, a depressão, essas são as feridas que jamais cicatrizam. (DIAS, 2007, p. 20).

Em geral, as vítimas só procuram as unidades quando o grau da violência está elevado. O agressor, que quase sempre é o companheiro, conhece o íntimo da vítima, conhece sua história, seus medos, seus sonhos, sabe exatamente como manipular e faz manobras para que 
ela se sinta merecedora das agressões ou que ele mudará. Nesse sentido, elucida Dias (2007, p.17):

É difícil denunciar quem reside sob o mesmo teto, pessoa com quem se tem um vínculo afetivo e filhos em comum e que, não raro, é o responsável pela subsistência da família. A conclusão só pode ser uma: as mulheres nunca param de apanhar, sendo a sua casa o lugar mais perigoso para ela e os filhos.

Dessa forma, as agressões nunca cessam, pelo contrário, tendem a aumentar gradativamente junto ao silêncio da vítima que não denuncia. É um ciclo que muitas vezes resulta em sua morte.

\section{AS MEDIDAS PROTETIVAS DE URGÊNCIA}

A medida protetiva de urgência é um instrumento jurídico que visa romper com o ciclo da violência doméstica, busca proteger os direitos fundamentais, conservar a existência física e moral das vítimas, enquanto estão à espera do sistema jurisdicional. A vítima, ao registrar a ocorrência da prática de violência doméstica, pode requerer imediatamente separação de corpos, alimentos, vedação de o (a) agressor (a) aproximar-se da vítima e de seus familiares ou que seja ele (a) proibido (a) de frequentar determinados lugares.

Adélia Moreira Pessoa, presidente da Comissão de Gênero e Violência Doméstica do IBDFAM diz que a Lei Maria da Penha trouxe um paradigma: "não podemos pensar apenas em responsabilizar o autor do delito, mas também ter um olhar de proteção integral à vítima, a medida protetiva é um dos caminhos" 3 .

A violência doméstica pode manifestar-se dentro ou fora do domicílio e incluir pessoas que passaram a assumir função parental, mesmo que sem vínculos de consanguinidade. Dessa forma, a Lei Maria da Penha elenca em seu Capítulo II, do artigo 22 aos 24, as medidas protetivas de urgência, sendo estas divididas em: Medidas Protetivas de Urgência que Obrigam o Agressor (art.22) e em Medidas Protetivas de Urgência à Ofendida (arts. 23 e 24).

Para obter as medidas protetivas, lavra-se o boletim de ocorrência na Delegacia de Polícia, requerendo a concessão da medida protetiva necessária ao caso. O delegado de polícia deverá remeter o pedido ao juiz, o qual deverá apreciá-lo em até 48 horas após o recebimento. Ressalta-se que as medidas protetivas poderão ser concedidas de imediato, independente de audiência das partes e de manifestação do Ministério Público, devendo este ser prontamente

\footnotetext{
${ }^{3}$ INSTITUTO BRASILEIRO DE DIREITO DE FAMILIA. Lei Maria da Penha: uma década de lutas e conquistas. 2016. <http://www.ibdfam.org.br/noticias/6076/Lei+Maria+da+Penha\%3A+uma+d\%C3\%A9cada+de+lutas+e+conqui stas>Acesso em: 20 de junho de 2019.
} 
comunicado. De acordo com o caso concreto e o agravamento da situação de violência, o juiz poderá aplicar mais de uma medida protetiva ou substituí-las a qualquer tempo por outras de maior eficácia.

As medidas protetivas que obrigam o agressor elencadas no art. 22 podem ser: a suspensão da posse ou restrição do porte de armas; afastamento do lar, domicílio ou local de convivência com a ofendida; proibição de aproximação do agressor com a vítima e/ou sua família; restrição ou suspensão de visitas aos dependentes menores; prestação de alimentos provisionais ou provisórios; comparecimento do agressor a programas de recuperação e reeducação; e acompanhamento psicossocial do agressor, por meio de atendimento individual e/ou em grupo de apoio.

A suspensão da posse ou restrição do porte de arma é essencial para a integridade física da vítima de violência doméstica e familiar, tendo em vista os dados assustadores que mostram a prática de crimes contra a mulher com arma de fogo. Ressalta-se que acaso haja a suspensão ou restrição do porte de armas o juiz comunicará ao órgão competente.

Sobre a proibição de aproximação do agressor da vítima e de sua família, é importante expor o fato de ser comum o agressor importunar tanto a vítima como seus familiares, razão pela qual a imposição de afastamento se faz necessária. Dessa forma para garantir sua a efetividade é essencial que o juiz ao deferir a medida protetiva, estabeleça limites mais precisos, determinando que o agressor se abstenha não apenas do âmbito doméstico, mas que seja estendido ao local de trabalho ou espaços de lazer da vítima.

Em maio de 2019, a lei Maria da Penha sofreu uma alteração pela lei 13.827/19, a qual autoriza, em determinadas hipóteses, a aplicação de medida protetiva de urgência pela autoridade judicial ou policial, em caso de violência doméstica ou familiar, à mulher vítima de violência ou a seus dependentes. Além disso, a norma também determina que seja feito o registro da medida protetiva de urgência em banco de dados mantido pelo CNJ.

\section{LEI 13.641/18 E O CRIME DE DESCUMPRIMENTO DA MEDIDA PROTETIVA}

A lei 13.641/18 incluiu o art. 24-A a LMP, trata-se de uma novatio legis incriminadora que tipificou como crime o descumprimento da medida protetiva. Durante um tempo sucessivas interpretações jurisprudenciais acerca da configuração ou não do crime de desobediência em caso de descumprimento resultaram em interpretações divergentes entre os Tribunais Estaduais. Por meio de decisões monocráticas de Ministros de ambas as Turmas Criminais do Superior Tribunal de Justiça, consolidou-se o entendimento no sentido da atipicidade. Entretanto, o 
posicionamento jurídico consolidado tornou-se incompatível com o espírito da Lei Maria da Penha, cujo propósito é ampliar e não restringir as hipóteses protetivas. Dessa forma, a ausência de norma que criminalizasse especificamente o descumprimento das medidas da Lei Maria da Penha acarretava enorme prejuízo ao sistema de proteção.

Assim sendo, tendo em vista os fins sociais a que a Lei Maria da Penha se destina, é de se reconhecer a importância da tipificação do crime de descumprimento da medida protetiva, haja vista que era muito comum, por exemplo, a vítima de violência deslocar-se até a delegacia de polícia para comunicar o descumprimento da medida protetiva pelo agressor e, no episódio, o delegado de polícia, na maioria das ocasiões, realizar apenas um registro "não criminal", comunicando ao juízo acerca do descumprimento ou proceder a representação policial para decretação da medida cautelar de prisão preventiva. Assim, o delegado de polícia coisa alguma podia fazer em advertência ao agressor, a não ser um mero registro da ocorrência comunicando ao juízo sobre o descumprimento da medida protetiva.

O novo crime é praticado por aquele que tem sobre si uma ordem judicial relativa às medidas protetivas de urgência, sendo possível ser tanto um homem quanto uma mulher, tendo em vista que a medida se aplica em relações homoafetivas. Ressalta-se que a nova lei não exclui a aplicação de outras sanções cabíveis. Conforme explica os delegados de polícia, Joaquim Leitão Júnio e Raphael Zanon da Silva o descumprimento da medida protetiva trata-se de um crime de ação penal pública incondicionada e o bem jurídico diretamente tutelado é Administração Pública, assim como o crime de desobediência previsto no Código Penal ${ }^{4}$.

Posto isso, ressalta-se que mesmo que a vítima possa comunicar o descumprimento da medida protetiva, para efetividade da norma deverá haver investimento em fiscalização para verificar se o agressor está descumprindo a medida, tendo em vista a vulnerabilidade que a vítima se encontra. O artigo 24-A é uma inovação, sendo assim, apenas com a aplicação reiterada, que os efeitos serão conhecidos.

\section{MECANismos ALternativos PARA FISCALIZAÇÃo DAS MEDIDAS PROTETIVAS}

Alguns entes federados têm desenvolvido mecanismos alternativos que visam aumentar

\footnotetext{
${ }^{4}$ JÚNIOR, Joaquim Leitão; SILVA, Raphael Zanon da. Impactos jurídicos da lei 13.641/18 e o novo crime de desobediência das medidas protetivas. Migalhas. Disponível em: <https://www.migalhas.com.br/dePeso/16,MI278510,91041impactos+juridicos+da+Lei+n+136412 018+e+o+novo+crime+de+desobediencia>. Acesso em 09 de julho de 2019.
} 
a eficácia da lei 11.340/06, bem como a fiscalização das medidas protetivas de urgência.

\subsection{Recursos Tecnológicos}

Diante do cenário de violência doméstica no Brasil, é preciso utilizar de todos os recursos, além dos meios tradicionais de denúncia. Conforme Ana Maria Amarante, coordenadora do Movimento Permanente de Combate à Violência Doméstica e Familiar do Conselho Nacional de Justiça (CNJ), se a tecnologia puder ajudar a salvar vidas, ela é muito bem-vinda 5 .

Nesse víes, o Município de Diamantina/MG lançou em 2018 o aplicativo Sistema Penha, idealizado pela delegada Kiria Silvia Orlandi, titular da Delegacia Especializada de Atendimento à Mulher (Deam) do Alto do Jequinhonha, em parceria com a Rede de Mulheres de Alto Jequitinhonha e a Universidade Federal do Vale do Jequitinhonha e Mucuri (UFVJM). De acordo com a delegada: "Os problemas da lei se resumem as questões de efetividade. A polícia tem muita dificuldade de fiscalizar as medidas protetivas concedidas pelo Poder Judiciário" ${ }^{6}$. O aplicativo busca reunir um banco de dados com as medidas protetivas deferidas ou revogadas pelo Judiciário, para facilitar a prisão em flagrante os agressores que descumprem as medidas protetivas impostas pela Lei Maria da Penha.

Para fiscalização das medidas protetivas de urgência, em 2013 o Tribunal de Justiça do Estado do Espírito Santo (TJES) em parceria com o Instituto Nacional de Tecnologia Preventiva (INTP) desenvolveram um Dispositivo de Segurança Preventiva (DSP), batizado como "Botão do Pânico". O aparelho, que já completou 06 anos de atuação, tem o objetivo de atender às mulheres em medida protetiva de urgência que se sintam ameaçadas. Um aliado no combate a violência doméstica o equipamento é um alerta para que a vítima seja socorrida, o acionamento é feito diretamente para a Guarda Civil Municipal ${ }^{7}$.

Sobre o assunto Rogério Sanches e Ronaldo Pinto (2018, p. 194) enfatizam a iniciativa implantada pelo Tribunal de Justiça de Minas Gerais, o qual adotou o emprego de tornozeleiras eletrônicas, objetivando acompanhar os passos dos agressores das vítimas de

\footnotetext{
${ }^{5}$ BRASIL. CONSELHO NACIONAL DE JUSTIÇA (CNJ). Tecnologias favorecem proteção às mulheres vítimas de violência. 2015. Disponível em: <https://www.cnj.jus.br/noticias/cnj/79658-tecnologias-favorecem-protecaoa-mulheres-vitimas-de-violencia>. Acesso em: 20 de abril de 2019.

${ }^{6}$ BRASÍLIA. Senado Federal. Procuradoria Especial da Mulher. A tecnologia a favor no combate a violência contra a mulher. Disponível em: <https://www12.senado.leg.br/institucional/procuradoria/comum/a-tecnologia-afavor-do-combate-a-violencia-contra-a-mulher>. Acesso em: 30 de julho de 2019.

${ }^{7}$ SILVA, Elza. Tribunal de Justiça do Espirito Santo. Botão do Pânico dispositivo de segurança que ajuda a proteger mulheres vítimas de violência domestica completa 06 anos. 2019. Disponível em: <http://www.tjes.jus.br/botao-do-panico-dispositivo-de-seguranca-que-ajuda-a-proteger-mulheres-vitimas-deviolencia-domestica-completa-6-anos/>. Acesso em: 30 de julho de 2019.
} 
violência doméstica. A monitoração eletrônica está prevista no art. 319, inciso IX, do Código de Processo Penal, foi incluída em 2011 pela lei 12.403. A ferramenta visa, sempre que possível, substituir a prisão preventiva, utilizando o GPS para acompanhar os passos do monitorado.

A principal diferença entre a monitoração eletrônica e o regime domiciliar é quanto às restrições. Em regime domiciliar, por exemplo, o preso possui restrições quanto aos horários que é permitido ficar fora de casa, enquanto um monitorado envolvido na Lei Maria da Penha não tem restrição de horários, mas de limites físicos. Além do uso da tornozeleira pelo agressor, a vítima recebe um dispositivo eletrônico que emite mensagem de texto a respeito da aproximação daquele, pelo celular, sendo também enviada a um centro de monitoramento, que aciona a polícia, visando impedir qualquer tipo de aproximação.

Cuidar dos passos de agressores por intermédio das tornozeleiras eletrônicas tem sido uma das formas encontradas para fiscalizar o cumprimento das medidas protetivas. A ação conta com o apoio do Conselho Nacional de Justiça (CNJ) e dos magistrados que compõem o Fórum Nacional de Juízas e Juízes de Violência Doméstica e Familiar contra a Mulher (FONAVID). Os juízes especializados em casos de violência doméstica durante a realização da $10^{\text {a }}$ edição do Fonavid recomendaram o uso das tornozeleiras eletrônicas ${ }^{8}$.

Além disso, o FONAVID editou o ENUNCIADO 36: "Poderá ser utilizado mecanismo compulsório de controle eletrônico em desfavor do agressor para garantia do cumprimento das medidas protetivas de urgência”.

Segundo Luciana Lopes Rocha, juíza e coordenadora do Núcleo Judiciário da Mulher do Tribunal de Justiça do Distrito Federal e Territórios (TJDFT), “o monitoramento possibilita verificar a obediência à decisão e traz mais segurança as vítimas, pois tende a inibir o descumprimento da medida protetiva pelo agressor". O juiz Ben-Hur Viza, um dos coordenadores do Núcleo Judiciário da Mulher em Situação de Violência Doméstica e Familiar do Distrito Federal (CJM/DF), explica: "Seja noite ou dia, a central de monitoramento registra o descumprimento de maneira eficaz, com precisão. O fato é comunicado à Justiça, que passa a ter maior controle sobre o caso. O equipamento também oferece mais segurança à vítima, pois a Central avisa quando o agressor se aproxima" 9.

\footnotetext{
${ }^{8}$ BRASIL. CONSELHO NACIONAL DE JUSTIÇA (CNJ). Violência doméstica: tornozeleiras garantem cumprimento de medidas protetivas. 2019. Disponível em: <https://www.cnj.jus.br/noticias/cnj/88413-violenciadomestica-tornozeleiras-garantem-cumprimento-de-medidas-protetivas〉. Acesso em: 30 de abril de 2019.

${ }^{9}$ TRIBUNAL DE JUSTIÇA DO DISTRITO FEDERAL E DOS TERRITÓRIOS. Juízes do TJDFT falam ao CNJ sobre tornozeleiras 
Além disso, o uso de tornozeleiras apresenta duas importantes vantagens: é mais econômico ao Estado e ajuda a reduzir a superlotação no sistema carcerário. De acordo com a Secretaria de Administração Penitenciária do Rio de Janeiro (Seap), o custo mensal de um preso no regime fechado é de $\mathrm{R} \$ 2.500,00$ em média, ao passo que o equipamento eletrônico custa $\mathrm{R} \$ 250,00$ a unidade.

Segundo o coordenador do Departamento de Monitoramento e Fiscalização do Sistema Carcerário do Conselho Nacional de Justiça DMF/CNJ), Luis Geraldo Lanfredi, nos casos de violência doméstica, a aplicação das tornozeleiras, acompanhadas de medidas pedagógicas, podem surtir mais efeitos práticos contra a violência do que o encarceramento. "É dever dos juízes conhecer e trabalhar com as ferramentas eficazes que dispomos", defende ${ }^{10}$.

Verifica-se que o monitoramento por sistema eletrônico de algemas digitais com GPS apresenta diversas vantagens no enfrentamento à violência doméstica familiar, posto que além do monitoramento do agressor, contribui para o caráter ressocializador da pena e coopera para recuperação da paz social e psicológica da vítima.

\subsection{Patrulha/Ronda Maria da Penha}

Em 2012, com iniciativa pioneira no Brasil, o Rio Grande do Sul idealizou a Patrulha Maria da Penha que começou sua atividade em Porto Alegre e atualmente está em 22 municípios, sendo ao todo 32 patrulhas. A Patrulha Maria da Penha realiza um acompanhamento assistencial às vítimas em sua residência sendo o auxílio de caráter multidisciplinar ${ }^{11}$.

Uma Patrulha Maria da Penha é composta por quatro policiais militares, que recebem cursos de capacitação para atenderem as vítimas, sendo dois homens e duas mulheres para que as vítimas se sintam mais confortáveis. Além disso, possui uma viatura diferenciada, evidenciando para a sociedade, principalmente para vizinhos e agressores, o engajamento do Estado na proteção das vítimas. A patrulha atua após a ocorrência do delito, fiscalizando o

\footnotetext{
<https://www.tjdft.jus.br/institucional/imprensa/noticias/2019/fevereiro/juizes-falam-ao-cnj-sobre-tornozeleiraseletronicas>. Acesso em: 30 de abril de 2019.

10 BRASIL. CONSELHO NACIONAL DE JUSTIÇA (CNJ). Violência doméstica: tornozeleiras garantem cumprimento de medidas protetivas. 2019. Disponível em: <https://www.cnj.jus.br/noticias/cnj/88413-violenciadomestica-tornozeleiras-garantem-cumprimento-de-medidas-protetivas >. Acesso em: 30 de abril de 2019.

${ }^{11}$ SANDER, Isabela. Patrulha Maria da Penha será ampliada no Rio Grande do Sul. Jornal do Comércio. 2018. Disponível em: <https://www.jornaldocomercio.com/_conteudo/2018/03/geral/615389-patrulha-maria-da-penhasera-ampliada-no-rio-grande-do-sul.html>. Acesso em: 30 de abril de 2019.
} 
cumprimento da medida protetiva e acompanhando as vítimas e seus familiares. Segundo Gerhard (2014, p. 107:

\begin{abstract}
A multidisciplinaridade ao atender uma ocorrência envolvendo a violência doméstica é primordial para existir eficiência e eficácia na ação da Polícia Militar a fim de que as mulheres se sintam mais protegidas e seguras. Com essa confiança a mulher irá, com certeza, denunciar seu algoz e procurar auxílio.
\end{abstract}

Nas visitas os policiais dialogam com a vítima para obter um retrato mais fiel do que se passa na residência. Depois, emite uma certidão e, no fim do mês, a Brigada Militar encaminha um relatório ao juiz responsável com o parecer relatando o que a Patrulha constatou para que a Justiça avalie o caso. Nas palavras de Gerhard:

\begin{abstract}
Nos casos em que a vítima informa para os policiais militares da Patrulha Maria da Penha de que está sendo importunada pelo agressor, que não aceita a separação, que tenta, por diversos meios (torpedos pelo telefone celular, mensagens por email, bilhetes, recados por vizinhos, visitas inoportunas, etc.), burlar e descumprir a decisão judicial, a Patrulha confecciona uma certidão para a DEAM, sugerindo que a prisão preventiva seja solicitada ao juizado em caráter de emergência, —Certidão de Vítima em Situação de Vulnerabilidade. Em casos mais graves, onde não há tempo para aguardar trâmites operacionais, requer diretamente ao Judiciário que a prisão preventiva do agressor seja decretada. (...) Essa ação preventiva e proativa dos policiais militares da Patrulha Maria da Penha afasta a priori o agressor da vítima. (GERHARD, 2014, p. 88 a 90)
\end{abstract}

Corrobora com esse entendimento o depoimento de um policial contido na obra "Patrulha Maria da Penha: o impacto da ação da polícia militar no enfrentamento da violência doméstica":

Depoimento 17: Durante o curso de capacitação da Patrulha Maria da Penha observei que em vários lugares inesperados pode haver uma mulher sendo agredida e em silencio por acreditar que se falar alguma coisa a alguém a situação pode piorar. E nós, como Policiais Militares, não podemos nos eximir de atuar nesses casos específicos. Depois de formado no curso ouvi vários relatos de mulheres que procuraram amparo da lei porque foram agredidas e que denunciaram apenas porque a Patrulha Maria da Penha deu o suporte e a proteção necessários. [...]

Soldado Robson Reolom $19^{\circ}$ Batalhão de Polícia Militar. (GERHARD, 2014, p. 214)

Conforme acima exposto, o contato da Polícia Militar garante segurança à vítima e aos seus familiares, bem como permite encorajar outras mulheres e até mesmo a sociedade a realizarem denúncias. Nesse entendimento expõe Gerhard:

Comprova-se que não apenas as vítimas se encorajaram e denunciaram seus agressores, mas a Patrulha Maria da Penha estimulou, na mesma intensidade, a comunidade no entorno dessa residência. Testemunhas oculares enxergam os maustratos; testemunhas auditivas escutam gritos e ameaças; testemunhas são vizinhos que reconhecem a violência que prospera dentro de um lar. Muitas vezes esse varão insuflado pela cultura machista, importuna e agride os próprios vizinhos, que se tornam vítimas, de certa forma, da violência doméstica acontecida em uma casa ao 
lado da sua. (GERHARD, 2014, p. 183).

Dessa forma, a Patrulha manda um claro recado ao agressor para que não mais se aproxime da vítima atendida, estimula outras mulheres a denunciarem, tranquiliza testemunhas a deporem e protege totalmente a vítima ofendida, conferindo paz a toda a comunidade que circunda a sua casa. (GERHARD, 2014, p. 245)

Devido ao sucesso do projeto, a patrulha teve seu modelo copiado por outros estados. Em Roraima a Patrulha Maria da Penha criada em 2015 pelo Tribunal de Justiça de Roraíma em parceria com o Município de Boa Vista conta com 12 guardas municipais. Só no $1^{\circ}$ semestre do ano de 2018, as equipes acompanharam 355 mulheres em situação de violência doméstica. ${ }^{12}$

Diante da constatação da falta de fiscalização e acompanhamento das medidas protetivas, a Polícia Militar da Bahia, iniciou em 08 de março de 2015, a operação especial denominada de Ronda Maria da Penha. Assim como a Patrulha Maria da Penha, a Ronda Maria da Penha tem como objetivo realizar visitas às vítimas de violência doméstica, beneficiadas por medidas protetivas de urgência, que segundo as avaliações encontram-se em situação de alta vulnerabilidade.

De acordo com Secretaria de Comunicação do Estado da Bahia, em pouco mais de dois anos, a Ronda fixou bases e equipes em Salvador, Feira de Santana, Juazeiro, Paulo Afonso, Vitória da Conquista e Senhor do Bonfim. Em 2019, a operação chegará a Barreiras e Ilhéus com equipes especializadas para realizar o acompanhamento das vítimas de violência doméstica $^{13}$. A Ronda é solicitada por toda Bahia, evidenciando a importância da fiscalização das medidas protetivas.

A Guarda Civil Municipal de João Pessoa realiza desde 2017, através da Ronda Maria da Penha, o monitoramento do cumprimento das medidas protetivas. No primeiro trimestre de 2019 foram realizadas 230 ações, uma média de três atendimentos por dia ${ }^{14}$.

A ronda faz parte do Programa de Enfrentamento à Violência contra a Mulher da Prefeitura de João Pessoa, fruto da colaboração do Tribunal de Justiça da Paraíba (TJ-PB) com a Guarda Municipal e a Secretaria Extraordinária de Políticas Públicas para mulheres (SEPPM) do município. O auxílio precisa ser permitido pela mulher, após o agressor ser

\footnotetext{
12 BRASIL. CONSELHO NACIONAL DE JUSTIÇA (CNJ). Patrulha Maria da Penha atende 355 mulheres no $1^{\circ}$ semestre em RR. 2018. Disponível em: <https://www.cnj.jus.br/noticias/judiciario/87523-patrulha-maria-dapenha-atende-355-mulheres-no-1-semestre-em-rr>. Acesso em: 28 de julho de 2019.

${ }^{13}$ GOVERNO DO ESTADO DA BAHIA. Sou mais a Bahia. Ronda Maria da Penha no combate à violência contra a mulher. Disponível em: 〈http://soumaisabahia.com.br/noticias/ronda-maria-da-penha/\#>. Acesso em: 30 de julho de 2019.

${ }^{14}$ JÚNIOR. Geri. Ronda Maria da Penha faz média de 2,5 atendimentos por dia a vítimas de violência domestica. Disponível em:<http://www.jornaldaparaiba.com.br/vida_urbana/ronda-maria-da-penha-faz-media-de-25atendimentos-por-dia-vitimas-de-violencia-domestica.html>. Acesso em: 30 de julho de 2019.
} 
notificado da medida protetiva. As decisões judiciais são avaliadas pela equipe técnica da SEPPM, que em seguida encaminha à Guarda Municipal. Para Adriana Urquiza, secretária de políticas públicas para as mulheres de João Pessoa, o projeto intensifica os números de denuncias $^{15}$.

De acordo com a Secretaria de Segurança Pública do Estado do Amazonas (SSP-AM), entre 2014 e 2018, cerca de mil mulheres receberam acompanhamento especializado por policiais militares que fazem parte do programa Ronda Maria da Penha em Manaus. "Nenhuma das mulheres atendidas foi vítima de feminicídio", segundo Adriane Oliveira, tenente da Polícia Militar responsável pela ronda ${ }^{16}$.

Verifica-se que muitas mulheres têm se beneficiado com os projetos da Patrulha e Ronda Maria da Penha, que garantem a fiscalização das medidas protetivas reduzindo a reincidência da violência pelo receio do agressor frente ao encorajamento da vítima.

\section{CONSIDERAÇÕES FINAIS}

Historicamente as mulheres foram tratadas com desigualdade em relação aos homens, mas após muitas lutas algumas conquistas foram galgadas. A luta da biofarmacêutica, Maria da Penha Maia Fernandes, foi tão exaustiva e com tamanha repercussão que se tornou símbolo do combate à violência doméstica e por tal motivo foi homenageada com a nomenclatura da lei 11.340/2006.

A referida lei contempla um rol não exaustivo das formas de violência: física, psicológica, sexual, patrimonial e moral. Apesar das inovações da Lei Maria da Penha, almeja-se que esta se torne realmente eficaz no combate à violência doméstica. Para isso, percebe-se a necessidade de uma fiscalização do cumprimento das medidas protetivas de urgência, com a mobilização de todos os componentes da segurança pública, para que de forma integrada seja garantida a proteção da vítima e de seus familiares.

Dessa forma, recursos tecnológicos como a tornozeleira eletrônica e o botão do pânico, podem auxiliar na fiscalização das medidas protetivas. Projetos como a Patrulha e

\footnotetext{
${ }^{15}$ JÚNIOR. Geri. Ronda Maria da Penha faz média de 2,5 atendimentos por dia a vítimas de violência domestica. Disponível em: $<$ http://www.jornaldaparaiba.com.br/vida_urbana/ronda-maria-da-penha-faz-media-de-25atendimentos-por-dia-vitimas-de-violencia-domestica.html>. Acesso em: 30 de julho de 2019.

${ }^{16}$ SECRETARIA DE SEGURANÇA PÚBLICA. Governo do Estado do Amazonas. Cerca de mil mulheres foram atendidas pela Ronda Maria da Penha em Manaus. 2018. Disponível em:<http://www.ssp.am.gov.br/cerca-de-mil-mulheres-foram-atendidas-pela-ronda-maria-da-penha-emmanaus/>. Acesso em: 30 de julho de 2019.
} 
Ronda Maria da Penha, desenvolvidos por agentes capacitados proporciona que as mulheres vítimas de violência doméstica se sintam seguras por intermédio das visitas e rondas nas imediações de suas residências, garantindo a efetiva quebra do ciclo da violência.

Conclui-se que os mecanismos alternativos estudados tornam mais eficazes as medidas protetivas regulamentadas pela Lei Maria da Penha e, consequentemente, a segurança das vítimas de violência doméstica. Dessa forma, as medidas alternativas devem ser difundidas por todo Brasil, de modo a proporcionar a diminuição dos índices de violência doméstica.

\section{Referências}

BRASIL. CONSELHO NACIONAL DE JUSTIÇA (CNJ). Enunciados. Disponivel em: $<$ https://www.cnj.jus.br/programas-e-acoes/lei-maria-da-penha/forum/enunciados $>$. Acesso em: 30 de abril de 2019.

\section{BRASIL. CONSELHO NACIONAL DE JUSTIÇA (CNJ). Patrulha Maria da Penha} atende 355 mulheres no $1^{\circ}$ semestre em RR. 2018. Disponível em:

<https://www.cnj.jus.br/noticias/judiciario/87523-patrulha-maria-da-penha-atende-355mulheres-no-1-semestre-em-rr>. Acesso em: 28 de julho de 2019.

\section{BRASIL. CONSELHO NACIONAL DE JUSTIÇA (CNJ). Tecnologias favorecem proteção} às mulheres vítimas de violência. 2015. Disponível em:

<https://www.cnj.jus.br/noticias/cnj/79658-tecnologias-favorecem-protecao-a-mulheresvitimas-de-violencia>. Acesso em: 20 de abril de 2019.

\section{BRASIL. CONSELHO NACIONAL DE JUSTIÇA (CNJ). Violência doméstica:} tornozeleiras garantem cumprimento de medidas protetivas. 2019. Disponível em: <https://www.cnj.jus.br/noticias/cnj/88413-violencia-domestica-tornozeleiras-garantemcumprimento-de-medidas-protetivas>. Acesso em: 30 de abril de 2019.

BRASIL. Lei 11.340, de 07 de agosto de 2006. Cria Mecanismos para coibir a violência doméstica e familiar contra a mulher e dá outras providências. Diário Oficial da União, 
Brasília, DF, de 08 de agosto de 2006. Disponível em: < http://www.planalto.gov.br/ccivil_03/_ato2004-2006/2006/lei/111340.htm> Acesso em: 19 de março de 2019.

BRASIL. Ministério da Mulher, da Família e dos Direitos Humanos. Balanço anual: Ligue 180 recebe mais de 92 mil denúncias de violações contra mulheres. 06 de agosto de 2019. Disponível em: <https://www.mdh.gov.br/todas-as-noticias/2019/agosto/balanco-anual-ligue180-recebe-mais-de-92-mil-denuncias-de-violacoes-contra-mulheres >. Acesso em: 19 de agosto de 2019.

BRASIL. Ministério da Saúde. Violência intrafamiliar: orientações para a prática em serviço. Brasília-DF: Ministério da Saúde, 2002.

BRASÍLIA. Senado Federal. Procuradoria Especial da Mulher. A tecnologia a favor no combate a violência contra a mulher. Disponível em:

<https://www12.senado.leg.br/institucional/procuradoria/comum/a-tecnologia-a-favor-docombate-a-violencia-contra-a-mulher>. Acesso em: 30 de julho de 2019.

CUNHA, Rogério Sanches; PINTO, Ronaldo Batista. Violência Doméstica: Lei Maria da Penha - 11.340/2006, Comentada artigo por artigo. $7^{\mathrm{a}}$ ed. rev. atual. e ampl. Salvador: Editora. JusPodivm, 2018.

DIAS, Maria Berenice. A lei Maria da Penha na justiça: a efetividade da Lei 11.340/2006 de combate à violência doméstica e familiar contra a mulher. São Paulo: Revista dos Tribunais, 2007.

FERNANDES, Maria da Penha Maia. Sobrevivi... Posso contar. $2^{\mathrm{a}}$. ed. Fortaleza: Armazém da Cultura, 2012.

FERNANDES, Tainah. O que é como enfrentar e como sair do ciclo da violência. Agencia Patrícia Galvão. Disponível em: <https://agenciapatriciagalvao.org.br/destaques/o-que-ecomo-enfrentar-e-como-sair-do-ciclo-da-violencia>. Acesso em: 10 de agosto de 2019. 
combate à violência contra a mulher. Disponível em:

$<$ http://soumaisabahia.com.br/noticias/ronda-maria-da-penha/\#>. Acesso em: 30 de julho de 2019.

JÚNIOR. Geri. Ronda Maria da Penha faz média de 2,5 atendimentos por dia a vítimas de violência domestica. Disponível em:<http://www.jornaldaparaiba.com.br/vida_urbana/ronda-maria-da-penha-faz-media-de25-atendimentos-por-dia-vitimas-de-violencia-domestica.html>. Acesso em: 30 de julho de 2019.

JÚNIOR, Joaquim Leitão; SILVA, Raphael Zanon da. Impactos jurídicos da lei 13.641/18 e o novo crime de desobediência das medidas protetivas. Migalhas. Disponível em: <https://www.migalhas.com.br/dePeso/16,MI278510,91041impactos+juridicos+da+Lei+n+13 6412 018+e+o+novo+crime+de+desobediencia>. Acesso em 09 de julho de 2019.

INSTITUTO BRASILEIRO DE DIREITO DE FAMILIA. Lei Maria da Penha: uma década de lutas e conquistas. 2016. Disponível em:

<http://www.ibdfam.org.br/noticias/6076/Lei+Maria+da+Penha\%3A+uma+d\%C3\%A9cada+ de+lutas+e+conquistas>. Acesso em: 20 de junho de 2019.

SANDER, Isabela. Patrulha Maria da Penha será ampliada no Rio Grande do Sul. Jornal do Comércio. 2018. Disponível em:

<https://www.jornaldocomercio.com/_conteudo/2018/03/geral/615389-patrulha-maria-dapenha-sera-ampliada-no-rio-grande-do-sul.html>. Acesso em: 30 de abril de 2019.

SECRETARIA DE SEGURANÇA PÚBLICA. Governo do Estado do Amazonas. Cerca de mil mulheres foram atendidas pela Ronda Maria da Penha em Manaus. 2018. Disponível em:<http://www.ssp.am.gov.br/cerca-de-mil-mulheres-foram-atendidas-pela-ronda-maria-dapenha-em- manaus/>. Acesso em: 30 de julho de 2019.

SILVA, Elza. Tribunal de Justiça do Espirito Santo. Botão do Pânico dispositivo de segurança que ajuda a proteger mulheres vítimas de violência domestica completa 06 anos. 2019. Disponível em: <http://www.tjes.jus.br/botao-do-panico-dispositivo-de- 
seguranca-que-ajuda-a-proteger-mulheres-vitimas-de-violencia-domestica-completa-6-anos/>. Acesso em: 30 de julho de 2019.

SOARES, Bárbara M. Enfrentamento a violência contra a mulher. Brasília. Secretaria Especial de Políticas para as mulheres. 2005. Disponível em: < https://www12.senado.leg.br/institucional/omv/entenda-a-violencia/pdfs/enfrentando-aviolencia- contra-a-mulher-orientacoes-praticas-para-profissionais-e-voluntarios >. Acesso em: 25 de julho de 2019.

TRIBUNAL DE JUSTIÇA DO DISTRITO FEDERAL E DOS TERRITÓRIOS. Juízes do TJDFT falam ao CNJ sobre tornozeleiras eletrônicas. Disponível em:

<https://www.tjdft.jus.br/institucional/imprensa/noticias/2019/fevereiro/juizes-falam-ao-cnjsobre-tornozeleiras-eletronicas>. Acesso em: 30 de abril de 2019. 